\title{
MODERNIDADE PEDAGÓGICA E MODELOS DE FORMAÇÃO DOCENTE
}

\author{
Marta Maria Chagas de Carvalho \\ Professora do Programa de Estudos Pós-Graduados em Educação: História, Política, Sociedade da PUC-SP e \\ Pesquisadora do Centro de Memória da Educação da USP
}

\begin{abstract}
Resumo: O artigo objetiva discernir, na proliferação dos discursos que, no Brasil, a partir do final do século XIX e nas primeiras quatro décadas do século XX, buscaram legitimar-se como saber pedagógico de tipo novo, moderno, experimental e científico, estilos distintos de organização do campo dos saberes representados como necessários à prática docente. Compreendendo o impresso destinado ao uso de professores como dispositivo de constituição desse campo, distingue dois modelos de formação docente inscritos na configuração material de revistas, livros e coleções que circularam no período: a "Caixa de Utensílios" e a "Biblioteca". Palavras-chave: pedagogia moderna; história da educação; ensino no Brasil.
\end{abstract}

A partir da segunda metade da década de 20 , são evidentes os sinais de que os modelos pedagógicos que vinham balizando as iniciativas de institucionalização da escola no Brasil, desde o final do século XIX, haviam esgotado a sua capacidade de normatizar as práticas docentes. Esse processo de corrosão foi marcado pelas motivações políticas, sociais e econômicas que constituíram as plataformas políticas e pedagógicas dos movimentos que Jorge Nagle chamou, em seus estudos sobre os anos 20, de entusiasmo pela educação e otimismo pedagógico. Dar conta desse processo implica, por isso, relacionar as mutações teóricas e doutrinárias produzidas no campo normativo da pedagogia às questões técnicas e políticas postas no processo de institucionalização da escola. Compreender esse processo de esgotamento de um modelo pedagógico é questão instigante que exige o concerto de uma pluralidade de perspectivas de análise. Sem pretender enveredar, neste texto, pela complexidade das questões que o tema suscita, procura-se recortar nele alguns tópicos, levantando hipóteses que permitam mapear esse processo e rastreando o impacto gradativo e nem sempre convergente de deslocamentos teóricos e doutrinários que determinaram o solapamento de cânones pedagógicos até então representados como portadores do novo em matéria pedagógica, assim como a sua substituição por um outro modelo. ${ }^{1}$ Toma-se, para tanto, o caso paulista.
Nas cinco primeiras décadas republicanas, dois modelos pedagógicos concorrentes configuram-se no Estado de São Paulo, pondo em cena estratégias diferenciadas de formação de professores. Na proliferação dos discursos que os articularam, dois estilos distintos de normatização das práticas escolares buscaram legitimarse como saber pedagógico de tipo novo, moderno, experimental e científico, produzindo estratégias concorrentes de configuração do campo dos saberes representados como necessários à prática docente.

No campo normativo da pedagogia moderna, que animou as iniciativas de institucionalização da escola no Estado de São Paulo a partir do final do século XIX, a pedagogia é arte de ensinar. Essa pedagogia estrutura-se sob o primado da visibilidade, propondo-se como arte cujo segredo é a boa imitação de modelos. Diferentemente, a chamada pedagogia da Escola Nova, que começa a se difundir no país em meados da década de 20, pretende subsidiar a prática docente com um repertório de saberes autorizados, propostos como os seus fundamentos ou instrumentos.

É no bojo das discussões que se desencadeiam sobre as medidas adotadas pela Reforma Sampaio Dória, em 1920, que começa a ganhar corpo em São Paulo a dissidência no campo normativo da pedagogia. As normas pedagógicas que vinham até então balizando o processo de institucionalização da escola paulista são postas em 
questão. Nessa luta de representações, duas posições se opõem, reivindicando para si, cada uma delas, o estatuto de pedagogia moderna e nova, porque ativa. Em meados da década, começa a se articular a posição que reivindica para personagens como Lourenço Filho e Fernando de Azevedo o estatuto de porta-vozes do movimento de renovação educacional que se processava no país e no exterior. Na disputa, uma questão ganha um contorno peculiar: diante das novas idéias pedagógicas que começavam a se difundir no país, que lugar atribuir às iniciativas de modernização pedagógica que, desde o início do século, vinham institucionalizando o modelo escolar paulista?

As posições em antagonismo coexistem nas décadas de 20 e 30 . A disputa é no sentido de dificultar o trabalho historiográfico, embaralhando a questão, já que muitos dos atores nela envolvidos movimentaram-se na contenda de modo muito fluído. Conhece-se muito bem a herança que a coexistência dessas duas posições legou no pastiche pedagógico que permeia a escola de todos nós. Porém, sabe-se muito pouco acerca das acomodações políticas e pedagógicas que produziram tal herança. Isso porque uma determinada memória foi legada pelos vencedores, que assenhorando-se do título de renovadores da educação, conseguiram expelir para o limbo da velha educação ou da pedagogia tradicional não somente os seus opositores, mas também muitos de seus precursores e aliados. Entretanto, encontraram forte resistência. Os seus opositores reivindicaram para si a herança das tradições pedagógicas institucionalizadas pelos republicanos históricos, erigindo-se em baluartes de defesa do modelo escolar paulista. Para compreender os termos dessa disputa, é interessante, aqui, remeter-se ao campo normativo da pedagogia moderna, que balizou as primeiras iniciativas republicanas de institucionalização da escola em São Paulo.

Tão logo proclamada a República, os governantes do Estado de São Paulo, representantes do setor oligárquico modernizador que havia hegemonizado o processo de instauração da República, investem na organização de um sistema de ensino modelar. É assim que a escola paulista, estrategicamente, constituiu-se signo do progresso que a República instaurava; signo do moderno que funcionava como dispositivo de luta e de legitimação na consolidação da hegemonia desse Estado na Federação. O investimento é bem-sucedido e o ensino paulista logra organizar-se como sistema modelar, em duplo sentido: na lógica que preside a sua institucionalização; e na força exemplar que passa a ter nas iniciativas de remodelação escolar de outros Estados.
Na lógica que preside a institucionalização do modelo escolar paulista, a pedagogia moderna é entendida como arte de ensinar, em que a prática da observação modula a relação ensino-aprendizagem, instaurando o primado da visibilidade (Rodrigues, 1930). A Escola Modelo anexa à Escola Normal é instituição nuclear. Com moderno e profuso material escolar importado e prédio apropriado, tinha como função a criação de bons moldes de ensino. ${ }^{2}$ Nela, os futuros mestres podiam aprender a arte de ensinar vendo "como as crianças eram manejadas e instruídas". Desse modo de aprender centrado na visibilidade e na imitabilidade das práticas pedagógicas, esperava-se a propagação dos métodos de ensino e das práticas de organização da vida escolar. Procedimentos de vigilância e orientação, acionados nos dispositivos de Inspeção Escolar, produziriam a uniformização necessária à institucionalização do sistema de ensino que a propagação do modelo pretendia assegurar. Dispositivos de produção de visibilidade de práticas exemplares, demonstrações na Escola Modelo, Relatórios de Inspetores e Anuários do Ensino testemunham o intento propagador e unificador da Diretoria da Instrução no processo de institucionalização do sistema escolar. Dessa estratégia republicana, resulta o modelo paulista que será exportado para outros estados da Federação: ensino seriado; classes homogêneas e reunidas em um mesmo prédio, sob uma única direção; métodos pedagógicos modernos utilizados na Escola Modelo anexa à Escola Normal e monumentalidade dos edifícios em que a instrução pública se faz signo do progresso. Viagens de estudo ao Estado de São Paulo e empréstimo de técnicos passam a ser rotina administrativa na hierarquia das providências com que os responsáveis pela instrução pública dos outros estados tomam iniciativas de remodelação escolar na Primeira República.

Para delinear o campo doutrinário da pedagogia que animou as primeiras iniciativas republicanas em São Paulo, é oportuno referir o relato sobre as práticas de sala de aula que faz o diretor da Escola Normal, Gabriel Prestes, em 1896. Em seu Relatório, há um repertório de convicções pedagógicas partilhadas que se organizam e dispõem: crença na eficácia inconteste dos processos de ensino intuitivo; concepções acerca da natureza infantil formuladas nos marcos de uma psicologia das faculdades mentais; aposta na pedagogia moderna como corpus de saberes e de instrumentos metodológicos aptos a viabilizar a escola de massas, organizando o ensino simultâneo em classes numerosas. É no ponto de convergência dessas convicções e desses propósitos que o exercício escolar 
configura-se como a base de estruturação do ensino na Escola Modelo. É em função desses exercícios que uma rotina escolar se estabelece; que o tempo se organiza como horário; que um percurso de aprendizagens se estabelece como programa disciplinar de estudos e como currículo; que as classes de alunos adquirem um perfil e que o espaço da sala de aula se estrutura. Na confluência dessas convicções e propósitos, o exercício escolar é dispositivo que permite alcançar um duplo objetivo: instruir e desenvolver as faculdades naturais da criança. É assim que, no Relatório, uma engenharia minudente estrutura o dia-a-dia escolar, dosando os exercícios, segundo critérios de medida das faculdades mentais das crianças e compondo-os de maneira a se valer de sua natural atividade. ${ }^{3}$

É oportuno relacionar essa engenharia às concepções pedagógicas que propunham a arte de ensinar como boa cópia de modelos. Falar aqui em cópia não tem o sentido pejorativo que iriam mais tarde lhe emprestar os seus críticos, no intuito de instaurar um novo paradigma de modernidade pedagógica. Falar aqui em cópia de modelos é falar em um tipo de atividade que, partindo da observação de práticas de ensinar, é capaz de extrair analiticamente os princípios que as regem e de aplicá-los inventivamente. Como prescrevia um Manual que, em 1911, o então diretor geral do Ensino em São Paulo, Oscar Thompson, mandaria traduzir e editar - A Arte de Ensinar: "É claro que o sucesso no ensino não depende de se copiar servilmente o método mais aperfeiçoado, mas de se apreender os princípios da arte de ensinar e de aplicálos inteligentemente na prática" (White, 1911).

A centralidade do exercício escolar no campo normativo da pedagogia indicia a lógica que preside a organização de impressos que, como a revista $A$ Eschola Pública, estruturam-se como caixas de utensílios para uso de professores, com seções de pedagogia prática compostas por roteiros ou modelos de lições. Nessa lógica, o exercício escolar é espécie de pauta musical que modula, dosa, aprimora e imprime ritmo à natural atividade da criança. Nela, todo um repertório de convicções pedagógicas converge na organização do impresso como caixa de utensílios destinados a promover a atividade do aluno regrada pelo exercício.

A arte de ensinar, tal como a concebia essa pedagogia moderna, é, assim, pedagogia prática. Nessa pedagogia das faculdades da alma, ensinar é prática que se materializa em outras práticas; práticas nas quais a arte de aprender formaliza-se como exercício de competências bem determinadas e observáveis em usos escolarmente deter- minados. Como artes de saber-fazer-com, ensino e aprendizagem são práticas fortemente atreladas à materialidade dos objetos que lhes servem de suporte. As práticas que se formalizam nos usos desses materiais guardam forte relação com uma pedagogia em que tal arte é prescrita como boa imitação de um modelo. Os incontáveis roteiros de lições divulgados em revistas dirigidas a professores têm as marcas dessa concepção pedagógica. Também a minudência modelarmente prescritiva dos assuntos arrolados nos manuais de pedagogia que compendiam as artes de ensinar as mantém. No âmbito dessa pedagogia, ensinar a ensinar é fornecer esses modelos, seja na forma de roteiros de lições, seja na forma de práticas exemplares cuja visibilidade é assegurada por estratégias de formação docente, preferencialmente dadas a ver em Escolas Modelo, anexas às Escolas Normais.

Sob o impacto de redefinições teóricas e doutrinárias de distinta extração, essa pedagogia como arte de ensinar foi sendo gradativamente solapada por iniciativas cujo denominador comum foi a pretensão de construir uma pedagogia científica. Talvez uma das mais ambiciosas e, por isso, mais caracterizada iniciativa de implantação de práticas então tidas como científicas no campo da Pedagogia tenha-se dado com a instalação, em 1914, do Laboratório de Pedagogia Experimental, no Gabinete de Psicologia e Antropologia Pedagógica, anexo à Escola Normal Secundária de São Paulo A instalação do gabinete foi justificada por Oscar Thompson, então diretor da Escola Normal. Teria o governo do Estado entendido "a conveniência de se ampliarem os estudos teóricos e práticos da pedagogia" e, por isso, havia criado o gabinete, além de uma Cadeira de Psicologia Aplicada à Educação. O objetivo da nova instituição pretendia ser o mesmo de similares estrangeiras, em especial norte-americanas: o "estudo científico" da infância, entendido como "exame metódico de todas as energias da criança" (Thompsom, 1914:17-18).

O processo de corrosão gradativa da concepção da pedagogia como arte de ensinar não esteve, no entanto, sempre atrelado às práticas de laboratório e à pretensão de construir uma pedagogia científica com elas. Como espécie de efeito colateral dessa pretensão, foi-se produzindo um outro tipo de deslocamento: a autonomização dos métodos de ensino. No campo da pedagogia entendida como arte de ensinar, o método não era dissociável da prática, das artes de fazer, do que decorria uma política de formação docente centrada na produção de condições materiais que favorecessem a imitação inventiva de modelos. 
Com toda a precaução que a matéria exige, é possível sustentar que a autonomização dos métodos que marca o solapamento dessa pedagogia como arte de ensinar deuse em duas direções distintas, mas complementares: a de um progressivo didatismo; e a de uma hipervalorização das "ciências" da educação como fundamentos da prática docente. Nesse processo, o impresso pedagógico didatizase em uma proliferação de discursos sobre os métodos ou sobre os fundamentos da prática docente.

Um dos marcos inaugurais desse processo de autonomização dos métodos talvez tenha sido o livro de Sampaio Dória, Princípios de Pedagogia, publicado em 1914. Nesse livro, o então professor da disciplina Psicologia, Pedagogia e Educação Cívica, da Escola Normal Secundária, estava interessado em justificar o emprego do " $m e ́$ todo intuitivo" - peça central nas estratégias republicanas de constituição de um sistema de educação pública modelar em São Paulo -, demonstrando tratar-se de método fundado no princípio de que a educação deveria recapitular, no indivíduo, o processo de evolução da humanidade. Esse tipo de esforço demonstrativo enraizava-se na tradição positivista que tanta penetração havia tido, desde o final do século XIX, na Escola Normal Secundária de São Paulo. Dispositivo de atrelamento da pedagogia ao evolucionismo spenceriano, a "lei da recapitulação abreviada" funcionava também, no livro de Sampaio Dória, como solapamento da pedagogia como arte, enraizando a prática docente no campo discursivo das prescrições metodológicas deduzidas de fundamentos científicos.

A tradição pedagógica de que Princípios de Pedagogia constitui-se um marco é produzida também pela ruptura que a chamada Reforma Sampaio Dória provocou na tradição anterior, abalando certezas e rotinas estabelecidas e produzindo polarizações nas discussões sobre o modelo escolar paulista. Porém, é somente a partir do final dos anos 20 que a pedagogia como arte de ensinar dá sinais inequívocos de que havia esgotado a sua capacidade de balizar a prática escolar no Estado de São Paulo. Índices da permanência ou ruínas de estratégias historicamente datadas de organização do campo da pedagogia, livros e revistas pedagógicas mantêm, em todo o período, as marcas dessa pedagogia como arte de ensinar, concorrendo com outros impressos, organizados segundo outras regras. A Revista do Ensino e a Revista Escolar são testemunhos da longevidade de um modo de conceber e organizar o campo normativo da Pedagogia, que guarda forte relação com a concepção da pedagogia como arte de ensinar, or- ganizando-se como caixa de utensílios e fornecendo modelos de lições e materiais para uso do professor. Também alguns manuais, recheados de "coisas para usar" ou de preceitos minudentemente práticos - por exemplo, os de autoria de João Toledo, Didática e Planos de Lição, publicados, respectivamente, em 1930 e 1934 -, são testemunhos dessa mesma longevidade. Perde-se nestes impressos, no entanto, a relação forte que essas modalidades de estruturação do impresso mantinham com as práticas de formação docente tal qual se configuraram no âmbito da pedagogia que animou as primeiras iniciativas republicanas em São Paulo.

No Inquérito promovido por Fernando de Azevedo, em 1926, são várias as evidências dessa luta de representações que cindia o campo educacional paulista. Entre muitas, as respostas de Lourenço Filho são especialmente enfáticas. Perguntado sobre o modo como a Reforma de 1925 tratava da "questão de assistência técnica e da inspeção e da fiscalização do ensino", responde: "Quanto à assistência técnica, louvo com o maior entusiasmo a idéia das medidas que a atual administração tomou a respeito, inspetores especializados e uma revista para professores. Se louvo a idéia, lamento, porém com sinceridade, e não sem tristeza, a sua execução. A 'Revista Escolar' parece uma pilhéria proposital ou obra de sabotagem" (Azevedo, 1926:148).

A cisão teria continuidade. Os episódios seguintes são pouco conhecidos, mas dignos de nota. Embora não seja possível tratar deles aqui, vale a pena mencionar dois deles: as rixas entre a Sociedade Paulista de Educação e a Diretoria Geral da Instrução Pública que se manifesta de modo inequívoco na disputa acerca da responsabilidade pela organização da III Conferência Nacional de Educação; ${ }^{4} \mathrm{e}$ a polêmica entre Sud Menucci e Renato Jardim em torno da escola paulista. Demarcando posições na disputa política pelo controle do sistema escolar paulista, esses episódios põem em cena a questão pedagógica que atravessava a disputa: o que era escola ativa? No entrecruzamento das posições que reivindicavam o estatuto de pedagogia moderna e nova, porque ativa, a questão ganhava um contorno peculiar: diante das novas idéias pedagógicas que se difundiam no país, provocando debates e gerando iniciativas de reforma escolar em outros Estados, que lugar atribuir à velha escola paulista que tantos anos de glória havia conhecido, impondo-se no país como modelo de modernidade pedagógica? É dessa disputa que a chamada pedagogia da escola nova emerge vencedora, reivindicando para si o monopólio do novo e do moderno e pro- 
duzindo, pejorativamente, os saberes pedagógicos concorrentes como pedagogia tradicional.

\section{LOURENÇO FILHO E A NOVA ESCOLA ATIVA}

Os múltiplos contatos de educadores brasileiros com o movimento pela escola nova que se desenrolava na Europa e nos Estados Unidos, no período entre-guerras, forneceram aos atores do movimento de renovação educacional brasileiro o acesso a um cardápio alargado de possibilidades de intervenção pedagógica. A determinação do crivo que selecionou as proposições pedagógicas difundidas deve levar em conta que, no Brasil, o processo de difusão da pedagogia da escola nova deu-se no âmbito do processo de institucionalização do forma escolar. ${ }^{5}$ Diferentemente da Europa, onde o movimento pela Escola Nova articulou-se como crítica de um modelo escolar plenamente instituído, no Brasil esse movimento defrontou-se com a situação-problema de sua não implantação na maior parte do país. Em muitas das reformas dos sistemas públicos de ensino que os chamados renovadores educacionais empreenderam nos anos 20 e 30, é essa situação-problema que determina a busca dos recursos técnicos, científicos e doutrinários que a nova pedagogia tornava disponíveis. Nas apropriações que foram feitas desses recursos, estava ainda em jogo a produção de condições materiais e técnicas para implantar o modelo escolar que, em outros países, tinha viabilizado a escola de massas: seriação, classes homogêneas, ensino simultâneo, regulamentação e uniformização do tempo escolar, enquadramento disciplinar, organização do espaço escolar, etc. Na produção dessas condições, a redefinição do conceito de atividade deveria ter um papel central, fazendo com que as práticas escolares passassem a ser reguladas por normas distintas daquelas que prescreviam a arte de bem ensinar como boa cópia de modelos e a arte de bem aprender como exercício das faculdades da alma.

A questão pode ser abordada no contexto das reformas dos sistemas de Instrução Pública promovidas, por todo o país, com o concurso dos chamados renovadores da educação, nas décadas de 20 e 30 . Tome-se o caso do Estado do Ceará, onde, em 1922, a pedido do governo cearense, Lourenço Filho é enviado de São Paulo, por indicação de Sampaio Dória, como técnico capaz de empreender a Reforma do sistema de ensino.

A Reforma pretendeu adaptar ao Ceará o modelo escolar paulista. De São Paulo, Lourenço Filho manda vir mobiliário, materiais e livros, distribuindo-os pelas esco- las. Como se ensina é um desses livros, de autoria de Sampaio Dória, em que é proposto o método de intuição analítica. Nos mesmos moldes da iniciativa paulista, Lourenço Filho organiza, ainda, a Escola Modelo, anexa à Escola Normal. Comentando a Reforma, na Revista $\mathrm{Na}$ cional,${ }^{6}$ um colaborador de Lourenço Filho assim descreve essa escola: "Instalada com material todo vindo de S. Paulo, e orientada por um professor paulista (...), o novo estabelecimento tornou-se, em pouco tempo, comparável a um grupo escolar do grande Estado. Foi aí que primeiro se introduziram as novas práticas escolares (a leitura analítica, o cálculo concreto, o ensino simultâneo da leitura e da escrita, o desenho do natural, o 'slodj', a cartografia, a ginástica sueca, etc.), práticas essas que, nesse instante, se irradiam por todos os grupos escolares da capital e do interior, como os clarões de uma nova era" (Craveiro, 1923:37).

Em 1930, Moreira de Souza, personagem muito atuante no movimento educacional que se aglutinava em torno da Associação Brasileria de Educação, realiza no Ceará uma nova Reforma da instrução pública. Reivindicando para as iniciativas da Reforma o monopólio do novo em matéria pedagógica, o reformador promove a desqualificação das iniciativas anteriores de remodelação das escolas cearenses, não poupando João Hippolyto de Azevedo e Sá, diretor da Escola Normal de Fortaleza, que havia sido um dos principais colaboradores de Lourenço Filho na Reforma de $1922 .{ }^{7}$

É nesse contexto de disputa entre modelos pedagógicos concorrentes que se inscrevem as questões formuladas a Lourenço Filho, em 1930, por João Hippolyto: a Reforma da Instrução Pública promovida em 1922 havia se pautado nos preceitos da pedagogia da escola nova? Ou teria sido ela concebida nos marcos da pedagogia tradicional? Promovera ela a escola ativa?

João Hippolyto já era diretor da Escola Normal quando Lourenço Filho foi alçado ao estatuto de reformador da instrução pública cearense. Em cartas de 1930, o velho diretor reclamava da desqualificação de que vinha sendo vítima. A indignação de João Hippolyto era justificada, afinal, não havia sido ele, João Hippolyto de Azevedo e Sá, o colaborador de Lourenço em uma reforma vazada nos mesmos princípios que norteavam a nova reforma?

Cautelosa, a resposta de Lourenço Filho espraia-se por inúmeros esclarecimentos e sugestões, na correspondência que dirige ao velho diretor da Escola Normal. Nela, apesar de toda a cautela, explicita-se o fosso existente entre 
a nova e a velha educação; entre a pedagogia moderna, que fizera a glória do modelo escolar paulista, e a pedagogia da escola nova, que vinha tomar o seu lugar. Escrevia Lourenço: "A princípio todo o ensino era verbal. Acreditava-se na magia da palavra, supunha-se mesmo que ela transmitisse as idéias. Foi ainda um pouco o ensino que aí eu encontrei (... ). Depois do movimento filosófico da Renascença, apareceu a nova concepção de formação genética do espírito: nada está na inteligência que não tivesse passado pelos sentidos. Como consequiência direta, o ensino de coisas, pelas coisas, ou intuitivo. Quanto tempo levou a implantar-se? Séculos e séculos, e ainda não dominou todas as escolas. Do começo deste século para cá, essa concepção tende a ser substituída por outra, a de uma filosofia pragmatista (a verdade é a utilidade), e de uma filosofia vitalista (além das impressões sensoriais há um quid, em cada indivíduo, que plasma as idéias a sua feição). O próprio pensamento para essa escola é ação: ação reduzida, mas ação. Ação reduzida e sistematizada pela linguagem, mas atividade. Daí, como conseqüência, não se pretender ensinar mais tão somente pela ação das coisas, mas pela ação do indivíduo, único capaz de organizar o espírito solidamente, para o seu fim normal: dirigir a ação." 8

A longa explanação que Lourenço Filho faz ao amigo, em tom professoral, é acompanhada de alguns esclarecimentos: as idéias nela contidas estavam sendo desenvolvidas em um "livrinho", que dizia estar "compondo", para “orientação do professorado" de São Paulo, pois, segundo o missivista, "a mesma confusão" que grassava no Ceará estaria alastrando-se entre os professores paulistas.

Moldar a escola segundo as novas teorias pragmatistas e vitalistas era tarefa a que - prosseguia Lourenço Filho - se haviam lançado diversos "sistemas" de pedagogia que vinham sendo criados, alguns mais avançados, outros menos. O sistema Decroly, por exemplo, era um destes. Ele poderia ser utilizado pelo amigo, sem que fossem necessárias grandes transformações nas rotinas da escola pública. Aplicá-lo não era ainda realizar a "escola ativa", proposta mais avançada, cuja aplicação estrita às escolas brasileiras envolveria transformações de tal monta que Lourenço as desaconselhava. Para que o amigo compreendesse bem a questão, Lourenço lhe enviava "um livrinho de Ferrière, o pai dessa escola", que ele havia feito "traduzir e publicar". 9

Entretanto, a questão colocada por João Hippolyto exigia maiores explicações e a correspondência alongava-se em novas explanações. As "idéias de renovação", escrevia, eram “mais extensas", não se circunscrevendo apenas a questões relativas à "técnica de ensinar" e à "ação do mestre". Elas incluiriam também "uma mais perfeita significação social da escola", a sua "adaptação ao meio físico e social". Disso a reforma do Ceará havia tratado, o que era "bem visível no livrinho do Craveiro, composto sob sua sugestão". As novas idéias incluíam também "uma composição mais perfeita das classes, pelo exame mental das crianças pelos testes". Outras coisas havia ainda para dizer ao velho diretor da Escola Normal, mas, não querendo "maçá-lo, indo além", Lourenço anunciava a expedição pelos correios de "vários livrinhos", que tinha "traduzido e feito traduzir". Esses "livrinhos" e mais aquele que estava "compondo" - Cinco lições sobre a escola nova ${ }^{10}$ - iriam ser de muita utilidade para o velho diretor. Havia, "indiscutivelmente", segundo Lourenço, "uma mudança a fazer-se no espírito do professorado quanto à filosofia do ensino", mas isso não poderia ser conseguido "de uma só vez". Dependeria de uma "lenta propaganda, de estudos e de experimentação".

As explanações dadas a João Hippolyto são complementadas por outras, compostas em tom menos professoral, desenvolvidas em carta dirigida a Moreira de Sousa. O tom da carta é, agora, de leve censura pela precipitação de algumas medidas de reformulação do ensino cearense tomadas pelo diretor geral, seu companheiro de militância na Associação Brasileira de Educação. Censura, também, ao modo como este vinha angariando inimigos e afastando possíveis colaboradores. A carta era uma resposta a uma consulta de Moreira de Sousa e uma cópia dela foi enviada a João Hippolyto. Censurando a inépcia de Moreira de Sousa, Lourenço queria provar-lhe, "por fatos", que a reforma de 22 havia deixado no Ceará "os germens do ensino ativo". Sugeria que o amigo lesse dois discursos que havia feito por ocasião da Reforma, citava algumas passagens desses discursos e falava das iniciativas que havia tomado, concluindo: "Digamos que eu não tenha razão. Digamos que a reforma não tenha feito senão ensino intuitivo. Isso já não seria pouco (...) Mas o ensino ativo é contra o ensino intuitivo? Não. É a lição dos mestres, e aliás, de bom senso. Na escola ativa a criança precisa agir. Mas agir sobre o quê? Sobre realidades, evidentemente, sobre coisas. (...) Nos seus artigos de polêmica, vejo que malsina demais o ensino intuitivo. Será talvez exagero consciente, para atrair a atenção para as novas idéias. Mas é uma concepção que não só desnorteia os professores, como, no caso, redunda em injustiça que o amigo certamente não desejou cometer" (Cavalcante, 1998:199). 
As censuras que Lourenço Filho faz a Moreira de Sousa não atingem toda a obra pedagógica do diretor da Instrução Pública cearense. Distinguindo entre escola nova e escola ativa, diz na mesma carta: "Obra notável que V. está fazendo é a tentativa de maior socialização da escola. Isso sim, é coisa que ninguém de bom senso pode discutir. Os centros de pais e mestres e as cooperativas escolares são uma obra notável. É escola nova e da boa. O eixo da escola nova é exatamente a maior socialização do trabalho escolar. Escola ativa é apenas um de seus capítulos" (Cavalcante, 1998:200).

Na polêmica entre o diretor da Escola Normal de Fortaleza e o novo diretor da Instrução Pública, contrapunham-se representações sobre a escola ativa. Os limites entre as novas propostas pedagógicas que a incensavam e as já velhas proposições sobre a atividade do aluno, centradas no exercício de suas faculdades, eram ao mesmo tempo tênues e nitidamente demarcados. Tênues porque percebê-los exigia conhecimento das mais recentes descobertas do campo da psicologia, assim como uma adequada compreensão das conseqüências desse conhecimento para a prática pedagógica. Nitidamente demarcados, pois, para os iniciados nas novas teorias psicológicas, tratava-se de uma verdadeira revolução no modo de conceber a atividade do aluno e de regrar a prática pedagógica capaz de favorecê-la. Todas as cautelas de Lourenço Filho com relação à implantação das novas idéias pedagógicas nas escolas públicas eram relativas à escola ativa e tinham o seu ponto nodal no preparo dos professores para implantá-la. Em São Paulo, segundo o missivista, a dificuldade havia mesmo ensejado a criação de um Instituto de Educação, uma "faculdade de ciências da educação", "justamente para divulgar a escola nova e a nova psicologia".

Respondendo a comentários que Sousa lhe enviara sobre algumas instituições paulistas que havia visitado, Lourenço aproveita a oportunidade para marcar, de modo mais nítido, o abismo existente entre as genuínas experiências de escola ativa que, segundo ele, vinham sendo realizadas em São Paulo sob o seu patrocínio, fora da rede pública, na Escola Rio Branco, e a precipitação inepta do amigo, manifestada na tentativa de implantar o mesmo tipo de escola no Ceará: "Estou muito penhorado à excelente impressão que deu a Escola Rio Branco, em artigo aí publicado. O trabalho nela continua, e este ano, com aspectos novos, magníficos. Mas das 11 classes que tenho, verdadeiro ensino ativo há apenas em três delas (...) $\mathrm{E}$ os seus professores foram meus alunos, recebem ins- truções diárias, lêem muito, sabem o seu tanto de psicologia e ganham de $600 \$$ a $1.000 \$$. Grandes óbices aí encontrará na dificuldade até de não poderem os professores adquirir livros. A escola ativa exige mestres muitos cultos, muito capazes, com espírito criador, com penetração psicológica. Senão é substituir uma rotina por outra" (Cavalcante, 1998:200-201).

A crítica à inépcia de Moreira de Sousa é incisiva. Nela, não é o mesmo tom professoral das explanações da carta a João Hippolyto que demarca o fosso entre a nova escola ativa e aquela fundada nos exercícios ativos do ensino intuitivo. Escreve Lourenço: "Você não dissimula que a escola ativa, que prega com tanto ardor, é um combate à reforma de 22 e ao ensino intuitivo. Ora, há nisso uma grave injustiça e, desculpe que lhe diga, um pouco de equívoco acerca do que seja a filosofia do ensino ativo. (...) Não se iluda. Ter programas de centro de interesse, fazer excursões e outras práticas mais ou menos ativas, sem mudança porém da mentalidade do professor e sem compreensão da nova psicologia do comportamento (o behaviorismo dos americanos) pode degenerar em anarquia e diminuição do rendimento do ensino. Será substituir uma rotina por outras, com essa desvantagem: da mais velha sabe-se o que é e o que dá. Da nova ninguém o pode afirmar"(Cavalcante, 1998:200).

Diversas no tom, as cartas dirigidas a João Hippolyto e a Moreira de Sousa são complementares nos conceitos que emitem, coincidindo no juízo de que a nova escola ativa propunha-se, ao mesmo tempo, como continuidade e como ruptura relativamente às práticas do ensino intuitivo. Elas discrepam, no entanto, em um ponto. Na carta a Moreira de Sousa, Lourenço afirma não haver escola ativa "sem mudança (...) da mentalidade do professor e sem compreensão da nova psicologia do comportamento (o behaviorismo dos americanos)". Já na correspondência a João Hippolyto, o fosso existente entre a velha e a nova escola ativa é explicado pelo impacto da "filosofia pragmatista (a verdade é a utilidade) e de uma filosofia vitalista (além das impressões sensoriais há um quid, em cada indivíduo, que plasma as idéias a sua feição)".

Qualquer que seja o entendimento de Lourenço Filho acerca das teorias psicológicas e filosóficas em jogo, é pertinente chamar a atenção para a situação discursiva que marca diferencialmente as duas enunciações. Na carta a Moreira de Sousa, tratava-se de articular uma crítica apontando para o que, do ponto de vista da fundamentação teórica, estava em jogo, sem supor que o seu interlocutor desconhecesse as mais modernas tendências no campo da 
pedagogia e da psicologia. Já a carta a João Hippolyto tinha a pretensão didática de ensinar ao velho diretor da Escola Normal um percurso que o levasse a superar suas concepções pedagógicas, introduzindo-o no campo teórico e normativo da nova pedagogia.

Partir dessa diferença entre as duas cartas pode ser aqui interessante para compreender as estratégias de divulgação da pedagogia da escola nova adotadas por Lourenço Filho no campo editorial.

Os "livrinhos" que Lourenço Filho promete enviar a João Hippolyto haviam sido editados como volumes da Biblioteca de Educação, coleção organizada por ele para a Companhia Melhoramentos de São Paulo. Pela data da correspondência, pode-se afirmar que os volumes enviados tenham sido todos ou alguns dos seguintes: Psicologia Experimental, de Henri Piéron; A Escola e a Psicologia Experimental, de Claparède; Educação moral e educação econômica, de Sampaio Dória; Temperamento e caráter sob o ponto de vista educativo, de Henrique Geenem; Educação e Sociologia, de Émile Durkheim; A hereditariedade em face da educação, por Otávio Domingues; Como se ensina Geografia, por Firmino Proença; A escola ativa e os trabalhos manuais, de Coryntho Fonseca; A lei biogenética e a escola ativa, de E. Claparède; Testes para a medida do desenvolvimento da inteligência, de A. Binet e Th Simon. ${ }^{11}$

No verso da folha de rosto das primeiras edições dos primeiros volumes da Coleção, a Editora publica um longo texto explanativo do perfil do destinatário e dos objetivos e características da iniciativa editorial. Nele se lê que a Coleção seria composta "de escolhidas traduções e de originais autores brasileiros, procurando desenvolver um plano harmônico, no seu conjunto, e tanto quanto possível perfeito, resumindo os mais salientes problemas educativos da atualidade". Cada volume conteria "sempre um assunto completo" e a coleção se distribuiria por duas séries. Na primeira, de "caráter geral", seriam expostas "as bases científicas do ensino, já do ponto de vista genético funcional da sua organização, já do ponto de vista da finalidade social e moral a que deve tender para a elevação do homem, como cidadão e como homem". $\mathrm{Na}$ segunda, seriam examinados "os meios práticos de educação e ensino, tratando-se de modo particular das aplicações que mais nos convenham, com indicações e críticas de sistemas". ${ }^{2}$

Organizados como "pequenos manuais" que condensam "as modernas idéias e práticas da educação" (Lourenço Filho, s/d (a)), os volumes da Coleção se dispõem como peças de um conjunto harmônico destinado a constituir a cultura pedagógica do professorado. A Biblioteca de Educação pretendia "ser mais que uma simples coleção de monografias úteis", teria "um plano organizado", que estava se desenvolvendo "com perfeita unidade". Ela encerraria "de um lado a exposição das bases sobre que a reflexão pedagógica pode apoiar-se, com proveito e, de outro, as aplicações, ensaios de didática, explicação e crítica de sistemas". Embora cada volume contivesse um "assunto completo", o conjunto visaria "formar um todo harmônico, desde as bases propriamente biológicas, às mais complexas indagações de natureza social e filosófica" (Lourenço Filho, s/d (b)).

Cotejadas com esses e com outros dispositivos de modelização da leitura dos livros da Biblioteca de Educação, como os prefácios e as notas de rodapé, as explanações do organizador da coleção na correspondência ao velho diretor da Escola Normal de Fortaleza delineiam o programa de uma política editorial cujo objetivo é a formação de uma nova cultura pedagógica. Nessa política, a Biblioteca de Educação é coleção que compendia os saberes pedagógicos necessários à transformação da mentalidade e da prática do professorado. Formar o professor é transformar a sua mentalidade. É fazê-lo percorrer o caminho que leva à superação de suas concepções sobre a atividade do aluno, deslocando-as do terreno constituído por uma pedagogia centrada no exercício das faculdades da criança. É levá-lo à compreensão das novas finalidades sociais da escola. Nesse programa, as representações de Lourenço Filho sobre as expectativas, disposições e competências de leitura do velho diretor da Escola Normal balizam o itinerário da "mudança a fazer-se no espírito do professorado quanto à filosofia do ensino" através do livro. Essas representações dão índices dos crivos que operaram a seleção dos títulos e assuntos que julgou oportuno editar de modo a promover aquela cultura pedagógica que considerava fundamental para a remodelação das práticas escolares segundo os novos princípios. Nessa perspectiva, é muito interessante observar que as explanações que faz a João Hippolyto são complementadas pela promessa de lhe enviar, pelos correios, "vários livrinhos", que tinha "traduzido e feito traduzir". Lourenço esperava que, "com os elementos" que remetia, João Hippolyto pudesse "ir experimentando alguma coisa na Escola Modelo", pois pretender tudo substituir de uma só vez seria "pura fantasia". Assim, o crivo que conforma a Biblioteca de Educação não é 
apenas constituído pelas concepções pedagógicas de Lourenço Filho, mas também pela avaliação que fez das disposições, expectativas e competências de seu público leitor - os professores e as professoras -, o que significa dizer que esse crivo foi também formado pela avaliação que o organizador da coleção fez acerca da aplicabilidade dos princípios e preceitos da pedagogia que era reivindicada como nova e ativa para as escolas brasileiras. Essa avaliação balizará as estratégias adotadas para promover a mudança pretendida de mentalidade do professorado, constituindo e organizando o campo dos saberes representados como necessários ao exercício da docência segundo critérios de adequação à realidade educacional do país.

Institucionalizar a escola no país não era mais tarefa que pudesse se circunscrever nos marcos da pedagogia moderna entendida como arte de ensinar. No campo normativo da nova pedagogia que passa a reivindicar para si o monopólio do moderno, o método é dissociado da prática, das artes de fazer, do que decorrem importantes deslocamentos nas estratégias de formação docente. A produção de condições materiais que favorecessem a imitação inventiva de modelos é substituída por estratégias que visam subsidiar a prática docente com um repertório de saberes autorizados, propostos como os seus fundamentos ou instrumentos. É essa nova estratégia que preside a configuração da Biblioteca de Educação nas duas séries referidas nas primeiras edições dos primeiros volumes da Coleção. Na primeira, de "caráter geral", seriam expostas, como já se viu anteriormente, "as bases científicas do ensino". Na segunda, apresentar-se-iam "os meios práticos de educação e ensino, tratando-se de modo particular das aplicações que mais nos convenham, com indicações e críticas de sistemas".

\section{NOTAS}

E-mail da autora: mcmarta@uol.com.br

1. Este artigo se inscreve nos marcos de uma pesquisa mais ampla que visa analisar estratégias editoriais de conformação dos saberes pedagógicos. Dessa perspectiva, a pesquisa analisa revistas, livros ou coleções destinados ao uso de professores como estratégias diferenciadas de formação docente, que, em situações históricas determinadas, organizam e constituem o campo dos saberes representados como necessários à prática docente. A pesquisa vem sendo desenvolvida com Bolsa de Produtividade de Pesquisa do CNPq.

2. Consultar, a respeito, os discursos e o Relatório de Caetano de Campos como Diretor da Escola Normal (Rodrigues, 1930:194-277).

3. Veja-se, por exemplo, o seguinte trecho do Relatório de Gabriel Prestes, sobre a Escola Modelo:"O ensino do primeiro ano, todo intuitivo quanto aos processos empregados, tem por objeto principal inspirar às crianças os hábitos de ordem e de trabalho, cultivando-se o poder da atenção de que eles são suscetí- veis. Mas como a natural atividade infantil faz com que o seu espírito não possa aplicar-se demoradamente sobre um mesmo objeto, o tempo escolar é subdividido em períodos de 15 minutos no máximo. Além disso, para manter-se um justo equilíbrio entre a atividade e a atenção que as crianças têm de manter, os exercícios são geralmente intercalados de marchas entre bancos, de canto ou de ginástica, que constituem verdadeiros períodos de recreio, em que as crianças descansam o espírito, predispondo-se para novos exercícios. Outro meio de que lançam mão as professoras para manter o espírito das crianças sempre disposto para o exercício das faculdades intelectuais que apenas desabrocham, é o de entretê-las com constantes ocupações apropriadas à sua tenra idade, ocupações que os americanos chamam de Busy-Work e que consistem em uma imensa cópia de pequenos exercícios tais como: a classificação de pedaços de papel de várias cores e tamanhos, (...) a reprodução de tecidos em papel ou outras tantas ocupações que se harmonizam com o gosto das crianças. Esse gênero de ocupações tem ainda a grande vantagem de permitir que se subdivida a classe, de modo que a mestra possa ocupar-se com menor número de alunos, enquanto os outros se entretêm aprazivelmente a trabalhar brincando e ao mesmo tempo desenvolvendo suas faculdades de observação" (Prestes, 1896:131).

4. A respeito da disputa ver Carvalho (1998, capítulos 2 e 5).

5. Sobre o conceito de forma escolar ver Vincent; Lahire e Thin (1994) e Pineau (1999).

6. Trata-se de Newton Craveiro, autor do livro de leitura adaptado ao meio cearense, João Pergunta (ou o Brasil Seco), que Lourenço Filho fez editar, para distribuição nas escolas cearenses.

7. Para mais informações sobre o assunto, ver Cavalcante (1998).

8. Essa carta é datada de 10 de março de 1930 e integra o acervo da família de João Hippolyto. Agradeço a Maria Juracy Maia Cavalcante por ter-me facultado o acesso a essa correspondência.

9. Trata-se do livro A lei biogenética e a escola ativa, vol. IX, da Biblioteca da Educação, coleção organizada por Lourenço Filho, para a Companhia Melhoramentos de São Paulo.

10. Ao que tudo indica, trata-se de Introdução ao Estudo da Escola Nova, que seria editado pela Biblioteca de Educação ainda em 1930. É interessante observar que na capa da primeira edição do segundo volume da Coleção - A escola e a psicologia experimental, de Claparède - consta a previsão de publicação de um livro de autoria de Lourenço Filho que parece nunca ter sido publicado: $O$ método em educação. Esse livro seria o volume IV da Coleção. O volume V, cuja publicação é anunciada na mesma capa, também não foi publicado: $O$ aprendizado ativo, por José Escobar.

11. Para dados sobre a coleção e, em particular, sobre as edições e a tiragem desses volumes, ver Monarcha (1997:27-59).

12. Esse texto consta das primeiras edições dos três primeiros volumes e não consta das primeiras edições dos volumes VIII e IX. Não foi possível obter acesso às primeiras edições dos volumes intermediários.

\section{REFERÊNCIAS BIBLIOGRÁFICAS}

AZEVEDO, F. A Educação na encruzilhada: problemas e discussões. (Inquérito realizado em 1926 pelo jornal O Estado de S. Paulo). São Paulo, Melhoramentos, s.d.

CARVALHO, M.M.C. Molde nacional e fôrma cívica: higiene, moral e trabalho no projeto da Associação Brasileira de Educação (1924-1931). São Paulo, USF, 1998.

CAVALCANTE, M.J.M. João Hippolyto de Azevedo e Sá. Um educador cearense. Uma investigação sobre o seu desaparecimento da história da Reforma "Lourenço Filho" e da educação no Ceará. Tese de concurso, Fortaleza, Universidade Federal do Ceará, 1998.

CRAVEIRO, N. “ A evolução do ensino no Ceará e a Reforma de 1922”. Revista Nacional. São Paulo, n.7, jul. 1923.

João Pergunta (ou o Brasil Seco). Ceará, Typ Progresso, 1924.

DOMINGUES, O. A hereditariedade em face da educação. São Paulo, Companhia Melhoramentos de São Paulo, s/d.

DORIA, A.S. Princípios de Pedagogia. São Paulo, Pocai-Weiss, 1914.

LOURENÇO FILHO. "Prefácio". In: PROENÇA, A.F. Como se ensina a Geografia. São Paulo, Companhia Melhoramentos de São Paulo, s/d (a). 
"Prefácio". In: DOMINGUES, O. A hereditariedade em face da educação. São Paulo, Companhia de Melhoramentos de São Paulo, s/d (b).

MENUCCI, S. A escola paulista. Polêmica com o sr. Renato Jardim. São Paulo, Copag, 1930.

MONARCHA, C. (org.). Lourenço Filho outros aspectos, mesma obra. Marília, Unesp/Mercado das Letras, 1997.

. "Lourenço Filho e a Biblioteca de Educação (1927-1941)". In: MONARCHA, C. (org.). Lourenço Filho outros aspectos, mesma obra. Marília, Unesp/Mercado das Letras, 1997.

NAGLE, J. Educação e sociedade na Primeira República. São Paulo, Rio de Janeiro, EPU/Fundação Nacional de Material Escolar, 1976.

PINEAU, P. "Premissas básicas de la escolarización como construcción moderna que construyó a la modernidad". Revista de Estudios del Curriculum, v.2, n.1, jan. 1999.
PRESTES, G. Relatório da Escola Norma apresentado ao Sr. Dr. Alfredo Pujol M.D. Secretário dos Negócios do Interior pelo Diretor Gabriel Prestes. São Paulo, Typografia do Diário Official, 1896.

PROENÇA, A.F. Como se ensina a Geografia. São Paulo, Companhia Melhoramentos de São Paulo, s/d.

RODRIGUES, J.L. Um retrospecto. Alguns subsídios para a história pragmática do ensino público em São Paulo. São Paulo, Instituto D. Ana Rosa, 1930

THOMPSON, O. "O futuro da pedagogia é científico". O Laboratório de Pedagogia Experimental. São Paulo, Tip. Siqueira, Nagel \& Comp., 1914.

VINCENT, G.; LAHIRE, B. e THIN, D. "Sur l'histoire et la theorie de la forme scolaire”. In: VINCENT, G. (dir.). L'Éducation prisionnière de la forme scolaire. Scolarization et socialisation dans les societés industrielles. Lyon, Presses Universitaires de Lyon, 1994.

WHITE, E. A arte de ensinar. Um manual para mestres, alunos e para todos que se interessem pelo verdadeiro ensino da mocidade. Trad. de Carlos Escobar. São Paulo, Siqueira Nagel \& Comp., 1911. 